\title{
FATIGUE BEHAVIOUR OF THREADED COUPLINGS - EXPERIMENTAL RESEARCH
}

\author{
Bruno Meertens ${ }^{1}$, Patrick De Baets ${ }^{2}$, Wim De Waele ${ }^{2}$, Jeroen Van Wittenberghe ${ }^{2}$ \\ ${ }^{1}$ Ghent University, Belgium \\ ${ }^{2}$ Ghent University, Laboratory Soete, Belgium
}

\begin{abstract}
In this article the fatigue behaviour of threaded connections is studied, as used in oil country tubular goods (OCTG). Some manufacturers have designed their own couplings (so called 'premium connections') and they claim having an improved fatigue life or better sealability. This study will compare different coupling designs with the standard API connection. The methods used to compare the different designs are based on two-dimensional finite element analyses. Experimental research is conducted to validate the results of the FEA. The experimental research consists of a 4-point bending fatigue test, which will result in a SN-curve for the threaded connection. Based on numerical and experimental results a performance factor is deduced for the particular connection design. This factor will be used to find the best design of threaded couplings. As eventual goal of this study, with the insights gained, a threaded connection with optimized fatigue life and sealability will be designed.
\end{abstract}

Keywords threaded connections, fatigue, experimental, finite element model

\section{INTRODUCTION}

Threaded connections are used to couple tubular members together. The coupling consists of a male member, also known as the pin, which is made up into a female part, also known as the box. Threaded connections are commonly used to connect pipe strings where it is not possible to connect them by welding because the pipes should be frequently coupled and uncoupled. This is especially the case for drill strings and offshore production risers.

In offshore applications, those connections are subjected to cyclic loads due to currents, the tide, movement of the oil platform... For drill strings the most common (between $65 \%$ and $75 \%$ [1-3]) failure modes of threaded connections are caused by fatigue. Failure of the connection is a costly problem in the oil and gas industry and it has a serious impact on the environment. Fatigue cracks in threads commonly occurs at the root of the last engaged thread (LET, Figure 1) $[4,5]$

Threaded connections can be divided in two main categories, standard connections and premium connections. Standard connections are defined by the API 5B and API 5L specifications [6, 7]. Premium connections are designed to have a better resistance to fatigue and/or optimised sealing properties.

The objective of this research is to define a performance factor. This performance factor can then be used to compare different threaded connection designs. The parameters in the performance factor should be found in numerical studies of the designs. After that, the numerical studies are validated by experiments.

The final goal of this study is to design a threaded connection with an optimised fatigue life and sealability.

\section{NUMERICAL RESEARCH}

\section{$2.12 \mathrm{D}$ axisymmetric model}

The performance analyses of threaded connections using finite element models are nowadays replacing the use of full-scale tests in the design phase. The model is a two dimensional axisymmetric model. The main advantage to use a 2D axisymmetric model compared to a full 3D model is the reduced calculation time and it is easier to change subtle details to the geometry. The disadvantage of the $2 \mathrm{D}$ axisymmetric model is that it does not take into account the thread helix and the thread runout region. Zhong A. [8] calculated the Von Mises stresses by means of a 3D FEA of a threaded connection and he showed that the stresses are approximately axisymmetric. Zhao et al. [9] showed that the threads can be modelled as an axisymmetric ring when the lead angle of the thread is small enough. Thus, the results of a 2D model are in good agreement with full 3D models. 


\subsubsection{Geometry}

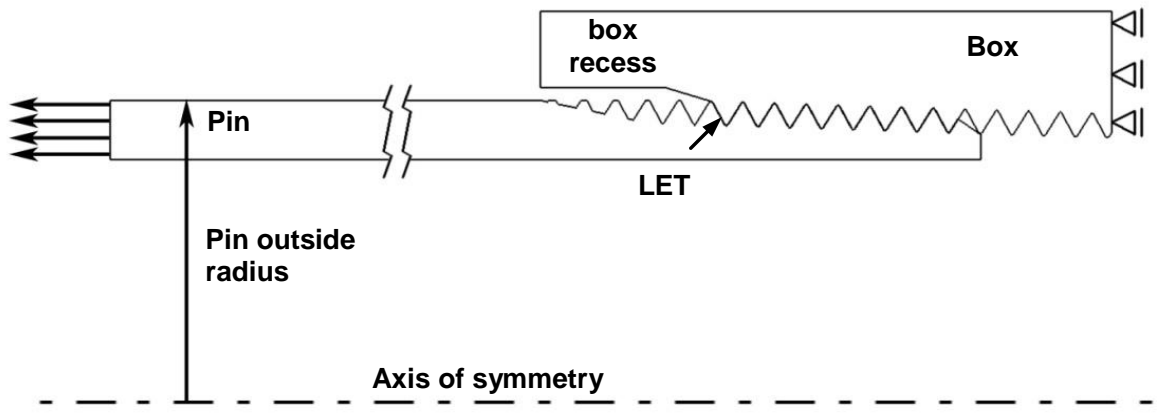

Figure 1: 2D axisymmetric model of the standard API Line Pipe connection

Figure 1 shows the 2D axisymmetric model of the standard API Line Pipe connection. The finite element analyses are carried out using the commercial FEA software package ABAQUS ${ }^{\circledR} 6.8-1$. The nominal size of the connection is 1 inch according to the API 5B specifications [6].

\subsubsection{Boundary conditions and loads}

Because the connection is symmetric, only a half connection is modelled. On the right side of Figure 1 the boundary conditions are defined in such a way that the model cannot move parallel to the axial direction, hence introducing a plane of symmetry.

To maintain a sealed and secured connection while being subjected to external loads, the connections are commonly preloaded. With conical connections (like the API line pipe connection) this can be done by tightening the pin and the box with a specified torque, the "make-up" torque. In a 2D axisymmetric connection make-up is modelled by an overlap on the threads of pin and box, corresponding to the specified number of make-up turns.

On the left side of Figure 1 the load is applied. The load is modelled as an axial surface stress. It is applied in 2 stages. First a load of $100 \mathrm{MPa}$ is applied, in a second stage the load increase to $150 \mathrm{MPa}$. Typical inservice values of stresses ranging from 30 to $150 \mathrm{MPa}[10]$.

\subsubsection{Material properties}

The material of the threaded connections is API Grade B steel with yield strength of $299.8 \mathrm{MPa}$, an ultimate tensile strength of $575 \mathrm{MPa}$. The corresponding elongation is $23 \%$. The model uses a Young's modulus of $208 \mathrm{GPa}$ and a poisson coefficient of 0.3 . The material properties match to the properties specified by API 5L [7] (Table 1).

Table 1: material properties specified by API 5L

\begin{tabular}{|c|c|c|c|c|}
\hline Material & $\begin{array}{c}\text { Yield Strength, } \\
\text { minimum } \\
{[\mathrm{MPa}]}\end{array}$ & $\begin{array}{c}\text { Yield Strength, } \\
\text { maximum } \\
{[\mathrm{MPa}]}\end{array}$ & $\begin{array}{c}\text { Ultimate Tensile } \\
\text { Strength, minimum } \\
{[\mathrm{MPa}]}\end{array}$ & $\begin{array}{c}\text { Ultimate Tensile } \\
\text { Strength, } \\
\text { maximum } \\
{[\mathrm{MPa}]}\end{array}$ \\
\hline Grade B & 241 & 448 & 414 & 758 \\
\hline
\end{tabular}

\subsection{Analyses of the standard API Line pipe and modified Line pipe connections}

\subsubsection{Standard connection}

The results from the FEA simulation are shown in the figures below. Figure 4 shows the relative distribution of the force over the thread of the connection. It can be seen that the LET take the greatest part of the load. Fatigue cracks nucleate at the root of the LET, because there the stresses are the highest (Figure 2). On Figure 5 the opening between the thread can be seen. This is defined as the perpendicular distance between the thread profile of the pin and the profile of the box. The threads are numbered as in Figure 3 . These results will be used to compare modified designs to the standard connection. 


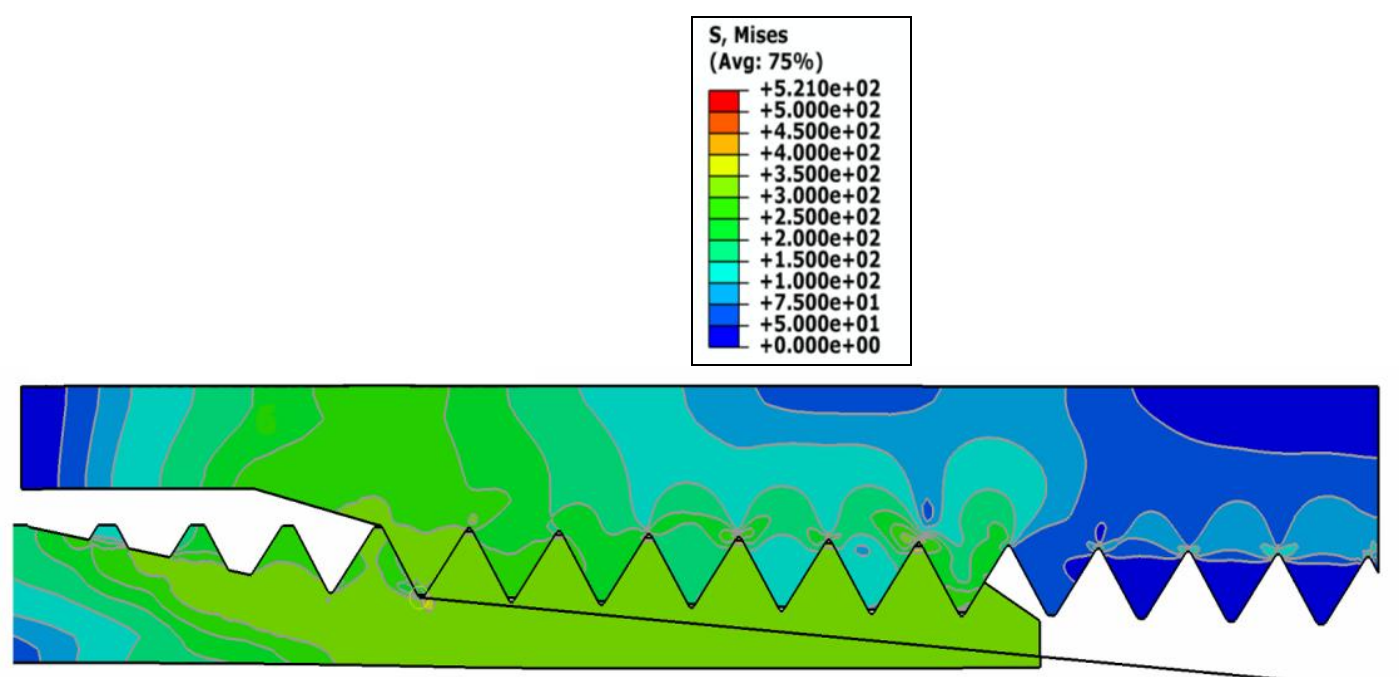

Max: $+5.004 \mathrm{e}+002$

Figure 2: stress distribution with a load of $100 \mathrm{MPa}$

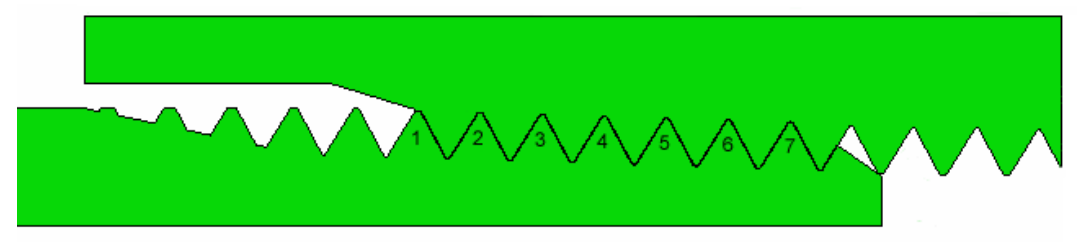

Figure 3: thread numbers

\section{Load distribution over the threads}

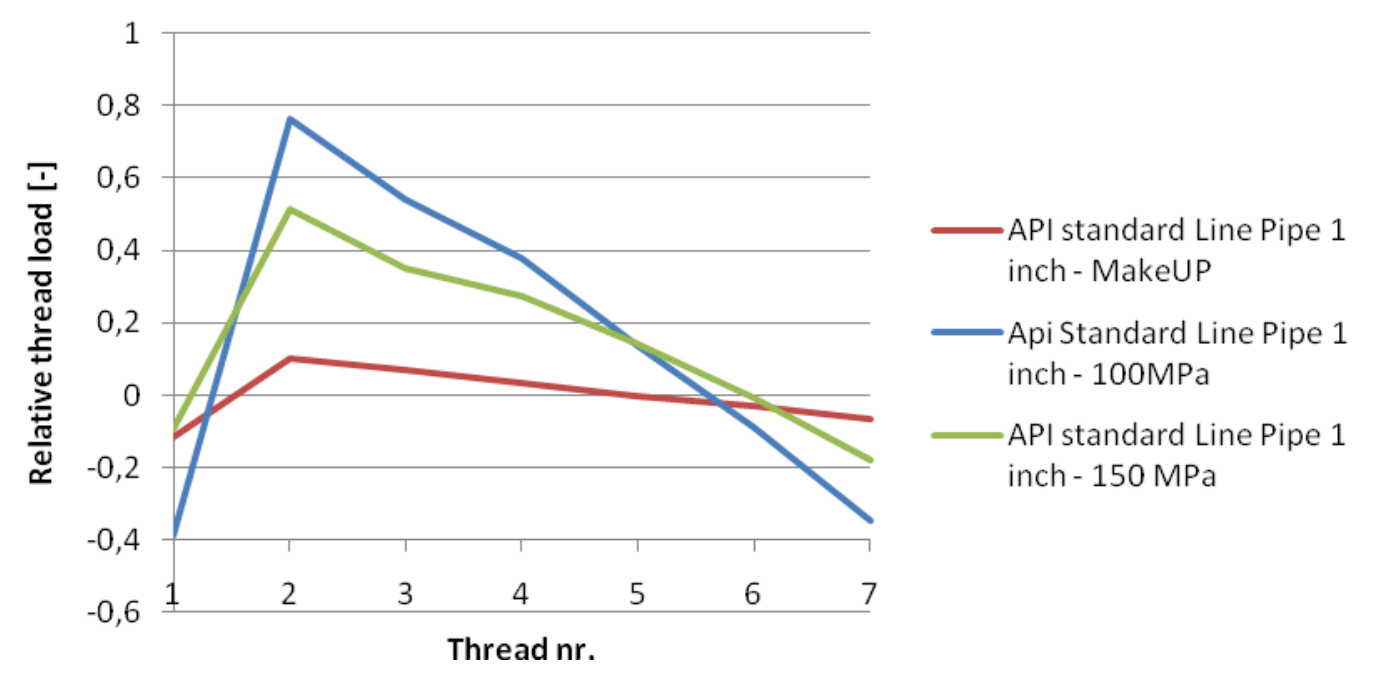

Figure 4: Thread load for the standard API line pipe connection 


\section{opening 1 inch norm}

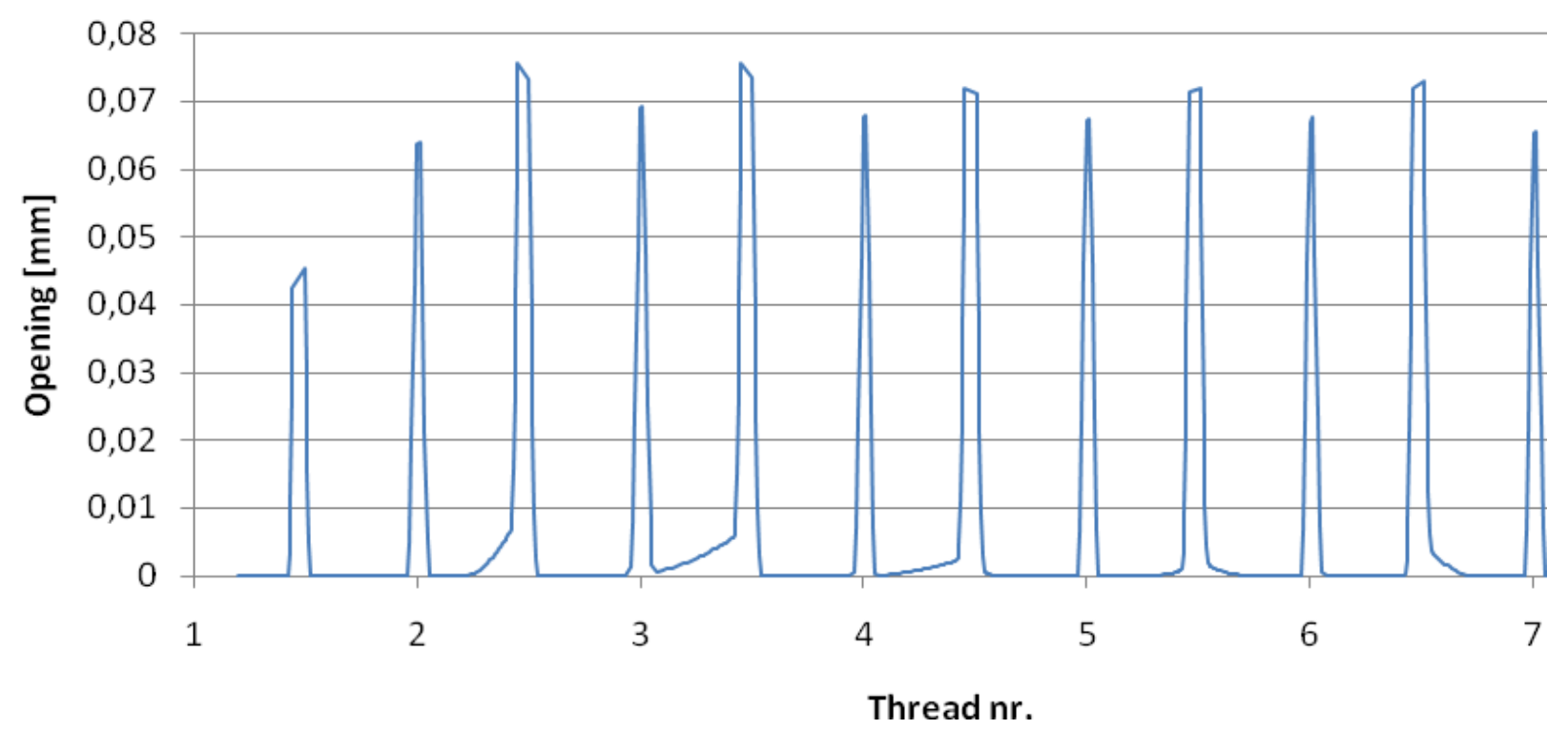

Figure 5: opening for the standard API line pipe connection

To compare the different coupling designs, the surface below the curve (Figure 5) will be used as a measure for the opening between the threads of the connection. For the standard 1" API Line Pipe connection, this surface is $0.1250 \mathrm{~mm}^{2}$.

\subsubsection{Modified connections}

To distribute the forces more evenly over all the threads the stiffness of the box is reduced. Due to the stiffness reduction, the box will deform a little more and the connection force will be better rearranged over the threads of the connection. This will reduce the stresses in the root of the LET and hence increasing the fatigue life of the connection. The principles of modified connections a-d (see Table 2) are based on stiffness reduction of the box.

The modified connections e-f use the principle that a reduced height of the LET will diminish the threadforce taken by the LET and thus reducing the stresses at the root of the LET.

Connection $g$ uses the principle of a stress relief groove to have a better flow for the stress and thus reducing the stress intensity factor in the root of the threads.

Table 2: Modified connections

a) Reduction of wall thickness of the box.




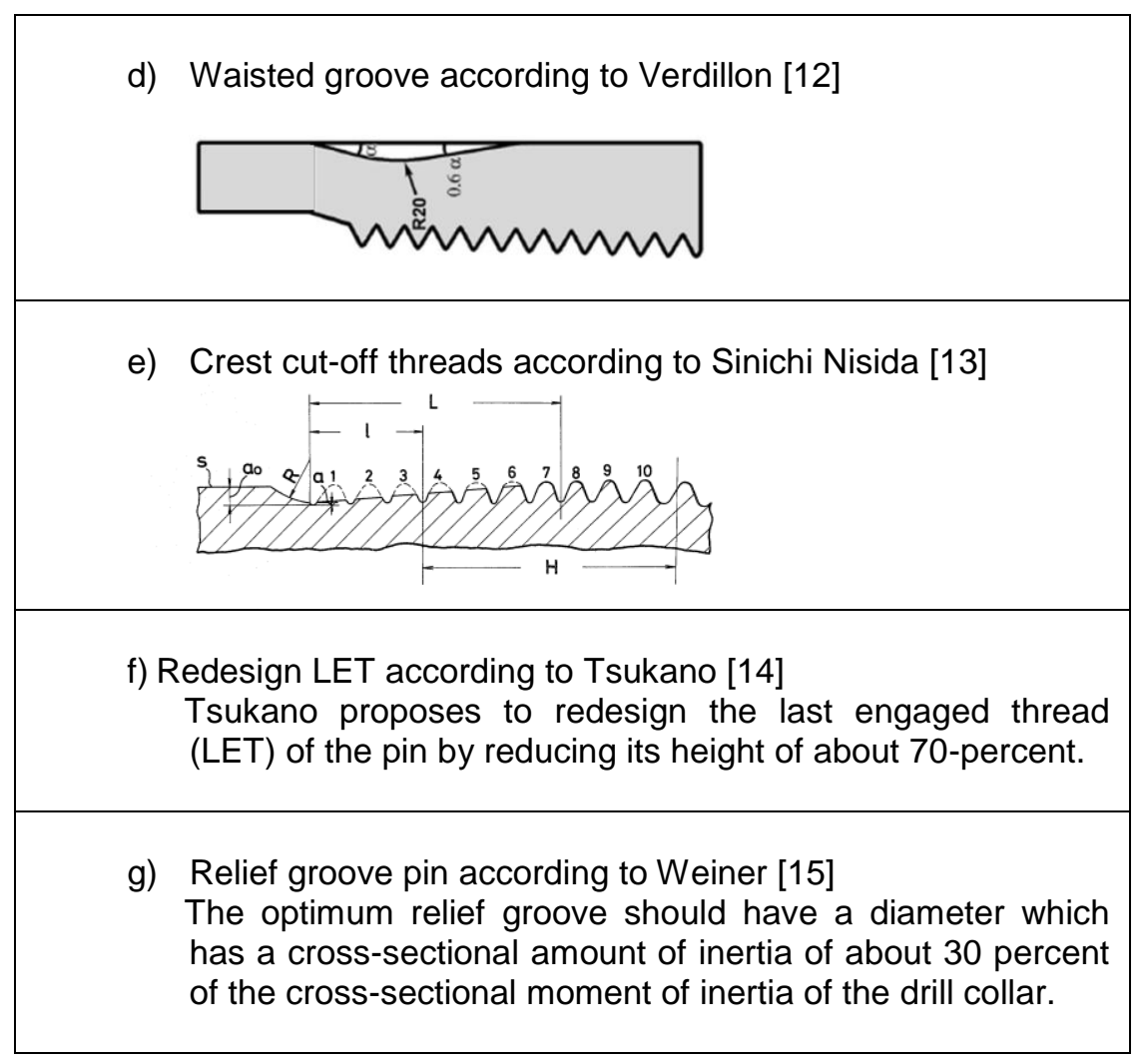

\subsubsection{Comparison between different connections}

The different designs will be compared when subjected to a load of $100 \mathrm{MPa}$, because with this load the FEA model is still mostly elastic.

\section{Load distribution over the threads}

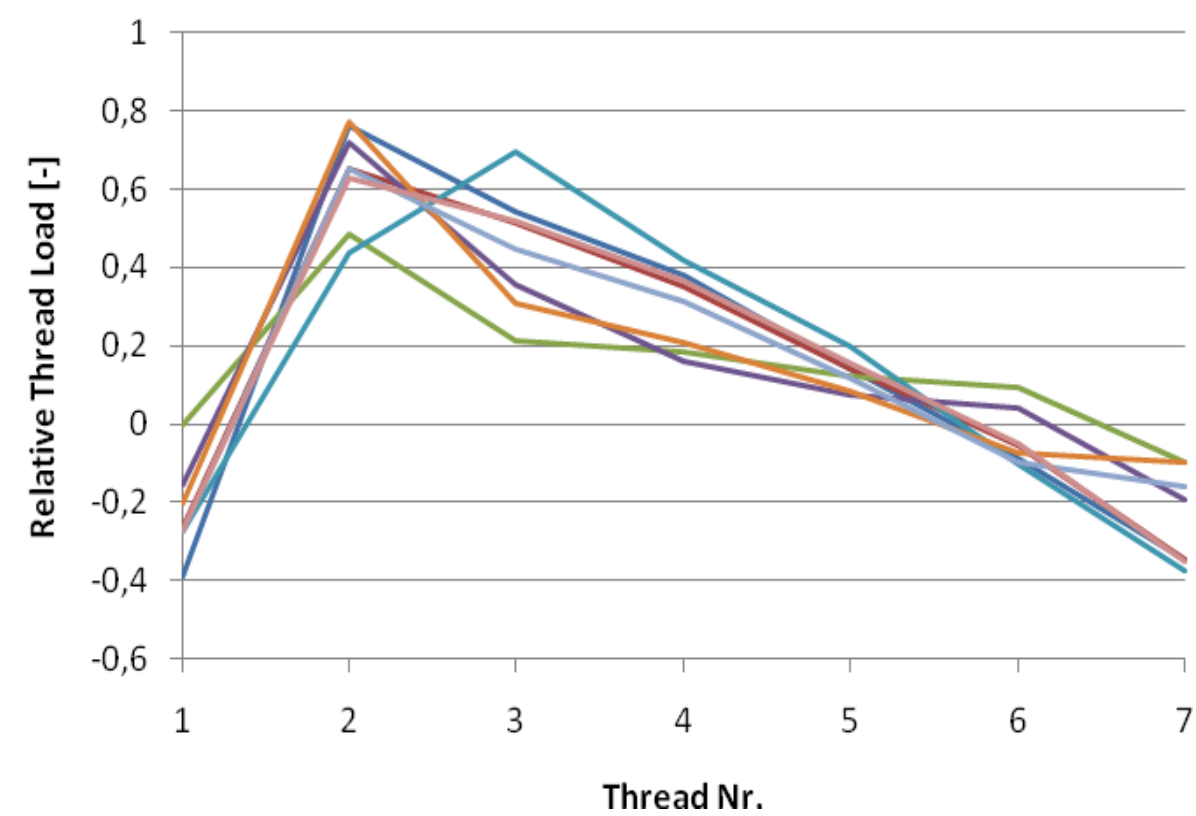

—APIGrB_1inch_norm

- Recess $-5 \mathrm{~mm}$

Wall Thickness $-2 \mathrm{~mm}$

— Patent 6752436

— Redesign LET

— Patent 4189975A

— Relief groove Pin

— Stiffness gradient $12^{\circ}$

Thread Nr.

Figure 6: Load distribution over the threads (100MPa)

The ideal connection should have the load distributed equally over all the threads. This is in practical condition never achieved, but the design that spread his load most evenly is the one where the wall thickness is reduced with $2 \mathrm{~mm}$. This connection has an optimised fatigue life, which will be validated with experimental tests. 
Table 3: Opening between threads

\begin{tabular}{|l|c|}
\hline \multicolumn{1}{|c|}{ Name connection } & $\begin{array}{c}\text { Surface below } \\
\text { opening curve [mm }\end{array}$ \\
\hline norm & 0.1250 \\
\hline Wall Thickness-1 & 0.1353 \\
\hline Wall Thickness -2 & 0.1409 \\
\hline recess-1 & 0.1390 \\
\hline recess -2 & 0.1388 \\
\hline recess -3 & 0.1385 \\
\hline recess -4 & 0.1380 \\
\hline recess -5 & 0.1373 \\
\hline Stiffness gradient $2^{\circ}$ & 0.1390 \\
\hline Stiffness gradient $4^{\circ}$ & 0.1388 \\
\hline Stiffness gradient $6^{\circ}$ & 0.1386 \\
\hline Stiffness gradient $8^{\circ}$ & 0.1383 \\
\hline Stiffness gradient $10^{\circ}$ & 0.1380 \\
\hline Stiffness gradient $12^{\circ}$ & 0.1376 \\
\hline Patent 6752436 & 0.1016 \\
\hline Patent 4189975A & 0.2582 \\
\hline Redesign LET & 1.12254 \\
\hline Relief Groove Pin & 0.1110 \\
\hline
\end{tabular}

A minimal value in Table 3 is desired to have an optimal seal capacity. The design with the smallest value is the design according to Verdillon [12]. Most of the connection designs are situated in a small range between $\left[0.10 \mathrm{~mm}^{2}-0.14 \mathrm{~mm}^{2}\right]$.

\section{EXPERIMENTAL RESEARCH}

\subsection{Description of the test setup}

A four-point bending fatigue setup will be used to validate the results of the numerical simulations. The test specimens are the same as those in the numerical simulations. They consist of two threaded pipe segments connected by a 1" API Line Pipe coupling or a modified coupling. The four-point bending setup gives a constant bending moment in the section comprising the coupling. This setup will measure the number of cycles which the coupling can sustain at a specified stress. To detect a failure, the connection is put under pressure. If a pressure reduction is observed, it means that there is a leak in the coupling and thus the connection has failed. The experimental program is part of the future work of this study.

\subsection{Comparison of $\mathrm{SN}$-curves from different premium connections}

To assess the fatigue life of a structure, SN-curves are commonly used. Figure 7 shows $\mathrm{SN}$-curves of different premium connection found in literature. The curves found by the 4-point bending fatigue test will be compared with the Wöhler-curves of the premium connection. The main objective of this research is to find a design with an optimal fatigue life. 


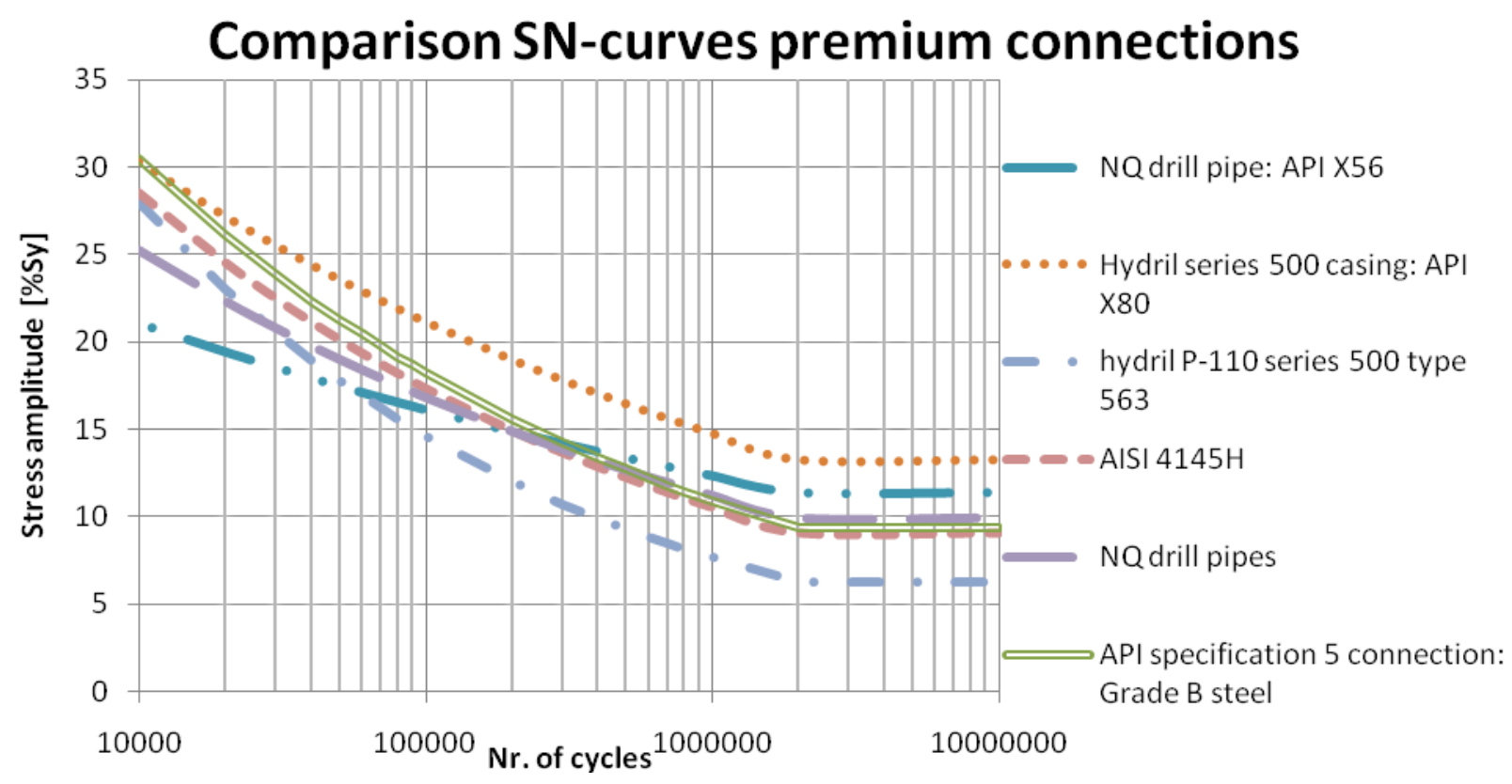

Figure 7: SN-curves premium connection

\section{PERFORMANCE FACTOR P}

A connection that has an excellent fatigue life but no sealing capacities is not usable in the oil and gas industry. This is why a performance factor is introduced. This is a factor in function of the thread opening ( $O$ ) and the distribution of the thread forces $(F)$ of the threaded connection. The thread forces are a measure for the fatigue life of the connection like mentioned above. To assess the sealing capacity of a connection, the opening between the thread of the coupling will be used.

$$
P(F, o)=\frac{\alpha * \frac{1}{F}}{\beta * o}
$$

\section{NOMENCLATURE}

\section{LET last engaged threads}

Pin male part of the connection

Box female part of the connection

$F \quad$ force

$\mathrm{N}$

o opening

$\mathrm{mm}$

\section{ACKNOWLEDGEMENTS}

The authors would like to acknowledge the financial support of the BOF fund (B/04939) of the Ghent University and of the FWO Vlaanderen (3G022806).

\section{REFERENCES}

[1] M. J. Knight, et al., "Controlled failure design of drillstring threaded connections," Fatigue \& Fracture of Engineering Materials \& Structures, vol. 26, pp. 1081-1090, Nov 2003.

[2] J. C. R. Plàcido, et al., "Fatigue Analysis of Aluminum Drill Pipes," Materials Research, vol. 8, pp. 409-415, 2005.

[3] G. F. Miscow, et al., "Techniques to characterize fatigue behaviour of full size drill pipes and small scale samples," International Journal of Fatigue, vol. 26, pp. 575-584, Jun 2004. 
[4] K. A. Macdonald and J. V. Bjune, "Failure analysis of drillstrings," Engineering Failure Analysis, vol. 14, pp. 1641-1666, 2007.

[5] L. Bertini, et al., "Fatigue on drill string conical threaded connections, test results and simulations," in International fatigue congress, Atlanta, Georgia, 2006.

[6] API, "API specification 5B," in Specification for threading, gauging and thread inspection of casing, tubing and line pipe threads (U.S. Customary Units), ed, 1996.

[7] API, "API specification 5L," in Specification for Line Pipe, ed, 2000.

[8] A. Zhong, "Thread Connection Response to Critical Pressures," Abaqus Users' Conference, pp. 690-706, Paris, France, May 2007.

[9] H. Zhao, et al., "Stress-intensity factor for a semi-elliptical surface crack at the thread root of a screwed-pipe joint," Computers \& Structures, vol. 59, pp. 419-424, May 1996.

[10] M. J. Knight and F. P. Brennan, "Fatigue life improvement of drill collars through control of bore eccentricity," Engineering Failure Analysis, vol. 6, pp. 301-319, Oct 1999.

[11] R. W. DeLange and M. E. Evans, "Threaded and coupled connection for improved fatigue resistance," US 6,609,735 B1, 2003.

[12] L. Verdillon, "Fatigue-resistant threaded bevelled tubular element," France Patent US 6,752,436 B1, 2004.

[13] S. Nisida, et al., "Screwed connection having improved fatigue strength," US 4,189,975, 1980.

[14] O. Vaisberg, et al., "Fatigue of drillstring: State of the art," Oil \& Gas Science and TechnologyRevue De L Institut Francais Du Petrole, vol. 57, pp. 7-37, Jan-Feb 2002.

[15] P. D. Weiner, "A means of increasing drill collor connection life," Journal of engineering for industry, ASME, vol. 95, pp. 243-246, 1973. 